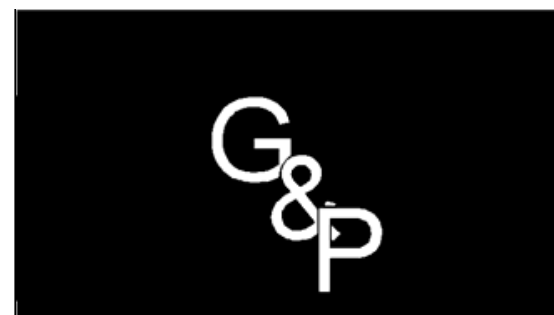

\title{
AVALIAÇÃO DE PROGRAMAS DE QUALIDADE MEDIANTE IMPLANTAÇÃO DA ISO 9000.
}

\section{GESTÃO} \&

\section{PRODUÇÃO}

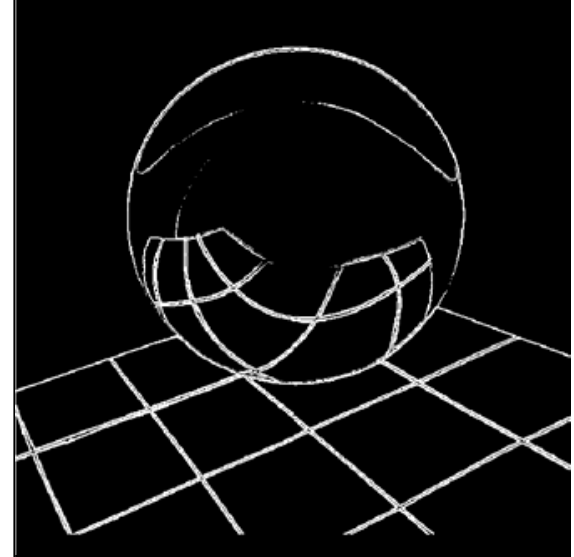

v.2, n.2, p. 162-172, ag0.1995
Guilherme Guedes Xavier

Professor do Departamento de Engenharia de Produção - EE.UFMG Rua Espírito Santo, 35 sala 717 - Belo Horizonte - MG - Brasil E-mail: XAVIER@BRUFMG.BITNET

\section{Resumo}

Interessado na disseminação de processos de implantação de Programas de Qualidade em empresas Brasileiras, o Grupo Nacional de Organização da Produção - GNOP realizou uma pesquisa sobre a avaliação desses programas, em empresas certificadas pela ISO 9000. Em uma primeira etapa, a pesquisa compreendeu o envio de um questionário aberto para empresas já certificadas, no Brasil, pela ISO 9000 (9001, ou 9002, ou 9003) e que tiveram a obtenção desse certificado divulgada por meio de publicações técnicas. A partir dos primeiros resultados, um segundo questionário, desta vez fechado, foi novamente enviado às empresas. Finalmente, as informações coletadas foram avaliadas por meio de visitas a doze empresas, escolhidas na região de atuação de cada uma das instituições que integram o GNOP. Neste trabalho são apresentados os principais resultados da pesquisa.

\section{Palavras-chave: ISO 9000, Garantia da Qualidade.}

\section{Introdução}

$\mathrm{N}$

os últimos tempos, ante os novos cenários competitivos, no Brasil e no mundo, o setor produtivo brasileiro vem sofrendo uma série de mudanças estruturais. Um dos fenômenos mais marcantes dessa reestruturação é a adoção, implantação e/ou consolidação, por parte das empresas, de Programas de Qualidade. Dentro desse contexto, o movimento pela certificação da ISO 9000, ou suas similares nacionais, tem se firmado como uma tendência definitiva para diversos setores da economia Brasileira. 
Interessado nessa tendência, um grupo de pesquisadores da Universidade Federal do Rio de Janeiro (Grupo de Produção Integrada), da Universidade Federal de Minas Gerais (Depto de Engenharia de Produção), da Universidade Federal do Rio Grande do Sul (Programa de Pós-Graduação em Engenharia de Produção) e da Escola Politécnica da Universidade de São Paulo (Núcleo de Estudos sobre Trabalho,
Tecnologia e Organização), reunidos em uma rede nacional denominada "Grupo Nacional de Organização da Produção" (GNOP), iniciou uma pesquisa com o objetivo de avaliar a implantação de "Programas de Qualidade" em empresas brasileiras, propondo caminhos para a adoção de uma visão estratégica voltada para a Qualidade (Informativo GNOP, maio/94, agosto/94, novembro/94)

\section{Série ISO 9000}

$\mathrm{P}$ ara melhor entender a pesquisa realizada, é interessante rever rapidamente o que é a série ISO 9000 . Trata-se, essencialmente, de um conjunto de requisitos básicos para a montagem de um Sistema de Garantia da Qualidade. Tais requisitos são colocados de acordo com o conjunto de atividades (processos) que a empresa realiza. Em um âmbito mais geral, em empresas verticalizadas, a implantação de um Sistema de Garantia da Qualidade que atendesse a ISO 9000, deveria incluir requisitos desde a parte de projeto e desenvolvimento de produtos até a assistência técnica, passando por instalações, produção, fechamento de contratos, etc.

Assim, as normas da série ISO 9000, ditas contratuais (9001, 9002 e 9003), se organizam de acordo com o âmbito dos processos, sendo a mais completa a ISO 9001 e a mais simples a ISO 9003. Na verdade, são essas normas que trazem os requisitos, conforme apresentado no quadro 1 , a serem atendidos, para que a empresa se habilite a receber o certificado.

\section{Quadro 1: Interrelacionamento entre as Normas}

\begin{tabular}{|c|c|c|c|}
\hline ISO & PROPÓSITO & TÍTULO & APLICAÇÃO \\
\hline 9000 & INTERNO & $\begin{array}{c}\text { Normas de Gestão da Qualidade } \\
\text { e Garantia da Qualidade - } \\
\text { Diretrizes para Seleção e Uso. }\end{array}$ & $\begin{array}{l}\text { Guia para auxiliar na } \\
\text { escolha da Norma } \\
\text { apropriada. }\end{array}$ \\
\hline 9001 & \multirow{3}{*}{$\begin{array}{l}\text { (SITUAÇÕES DE } \\
\text { CONTRATAÇÃO) }\end{array}$} & $\begin{array}{l}\text { Sistemas da Qualidade - Modelo } \\
\text { para Garantia da Qualidade em } \\
\text { Projeto/ Desenvolvimento/ } \\
\text { Produção/Instalação e Assist. } \\
\text { Técnica. }\end{array}$ & $\begin{array}{l}\text { Utilizado quando o } \\
\text { fornecedor deve garantir } \\
\text { todos os estágios do } \\
\text { processo, desde o projeto } \\
\text { até a Assist. Técnica. }\end{array}$ \\
\hline 9002 & & $\begin{array}{l}\text { Sistemas da Qualidade - Modelo } \\
\text { para Garantia da Qualidade em } \\
\text { Produção e Instalação. }\end{array}$ & $\begin{array}{l}\text { Utilizado para fornecedor } \\
\text { de produtos, quando o } \\
\text { projeto já está concluído. }\end{array}$ \\
\hline 9003 & & $\begin{array}{l}\text { Sistemas da Qualidade - Modelo } \\
\text { para Garantia da Qualidade em } \\
\text { Inspeção e Ensaios Finais. }\end{array}$ & $\begin{array}{l}\text { Utilizado para fornecedor } \\
\text { com requisitos somente de } \\
\text { inspeção e ensaios finais. }\end{array}$ \\
\hline 9004 & INTERNO & $\begin{array}{l}\text { Administração da Qualidade e } \\
\text { Elemento de Sistemas da } \\
\text { Qualidade - Diretrizes. }\end{array}$ & $\begin{array}{c}\text { Critérios para implantação } \\
\text { de um sistema da Qualidade } \\
\text { numa empresa. }\end{array}$ \\
\hline
\end{tabular}


requisitos específicos, mas considerações a respeito desse Sistema de Qualidade. Assim, a ISO 9000 traz informações para que uma empresa possa situar seu conjunto de processos e verificar se ela deve atender a ISO 9001, ou ISO 9002, ou ISO 9003. A ISO 9004, por sua vez, trata de princípios gerais referentes a Qualidade, estando mais próxima daqueles conceitos apresentados em programas de Qualidade Total. De qualquer forma, nem a ISO 9000 nem a ISO 9004, são objeto de auditoria para a certificação.

A ISO 9004, conforme mostra o quadro 2, apresenta conceitos e princípios gerais agrupados em 21 itens (de 0 a 20). Por sua vez, estes conceitos gerais são desbobrados em requisitos nas normas contratuais. É o atendimento de cada um desses requisitos, que habilita uma empresa a receber o certificado de que atende a ISO 9000. No quadro 3 tem-se a correspondência entre os princípios gerais e o seu desdobramento em requisitos.

Um aspecto interessante a ser ressaltado, é que dentro dos princípios estabelecidos pelos comitês ISO, as normas devem sofrer um processo contínuo de avaliação e aprimoramento. Assim é que, em julho de 94 foi publicada uma nova versão da série ISO 9000. Porém, esta nova versão não apresenta uma reformulação global, mas pequenos ajustes em relação à anterior. Estes pequenos ajustes foram incorporados às normas brasileiras em dezembro de 1994. Espera-se para 1998 uma reformulação global.

\section{Quadro 2: ISO 9004 - Enfoques Principais}

\begin{tabular}{|c|c|}
\hline DIVISÃO & ENFOQUES PRINCIPAIS \\
\hline 0. INTRODUÇÃO & $\begin{array}{l}\text { - missão da empresa - satisfação das pessoas (acionistas, funcionários, } \\
\text { clientes e sociedades). } \\
\text { - necessidade da companhia/usuários. } \\
\text { - riscos, custos e benefícios. }\end{array}$ \\
\hline $\begin{array}{l}\text { 1. ESCOPO E CAMPO } \\
\text { DE APLICAÇÃO }\end{array}$ & $\begin{array}{l}\text { - descrever a finalidade da norma: elementos do sistema da qualidade } \\
\text { e seleção da norma apropriada. }\end{array}$ \\
\hline 2. REFERÊNCIAS & - demais normas iso 9000 a 9003. \\
\hline 3. DEFINIÇÕES & - são as definições básicas (cf.iso 0482) \\
\hline $\begin{array}{l}\text { 4. RESPONSABILIDA- } \\
\text { DES DA ADMINIS- } \\
\text { TRAÇÃO }\end{array}$ & $\begin{array}{l}\text { - comprometimento da alta administração com a qualidade . } \\
\text { - política da qualidade definida pela alta administ. } \\
\text { - estrutura organizacional compatível. } \\
\text { - sistema eficaz e ênfase na prevenção de problemas. }\end{array}$ \\
\hline $\begin{array}{l}\text { 5. PRINCÍPIOS DO } \\
\text { SISTEMA DA QUA- } \\
\text { LIDADE }\end{array}$ & $\begin{array}{l}\text { - envolve todas as atividades em todas as fases desde a identificação } \\
\text { dos requisitos e expectativas dos clientes até satisfação final destes. } \\
\text { - ciclo da qualidade (mercadologia até assist. técnica). } \\
\text { - estrutura do sistema da qualidade (estrutura, recursos, pessoal, } \\
\text { equipamentos, facilidades, procedimentos). } \\
\text { - documentação do sistema (política, manual, planos e registros de } \\
\text { qualidade). } \\
\text { - auditorias do sistema (plano, execução, relatórios e avaliação da } \\
\text { gestão da qualidade). }\end{array}$ \\
\hline $\begin{array}{l}\text { 6. } \\
\text { ECONOMIA - CON- } \\
\text { SIDERAÇÕES SO- } \\
\text { BRE CUSTOS RE- } \\
\text { LACIONADOS COM } \\
\text { A QUALIDADE }\end{array}$ & $\begin{array}{l}\text { - envolve a implantação de um sistema de custos da qualidade } \\
\text { (avaliação, prevenção, falhas internas e falhas externas). }\end{array}$ \\
\hline
\end{tabular}




\begin{tabular}{|c|c|}
\hline $\begin{array}{l}\text { 7. QUALIDADE EM } \\
\text { MERCADOLOGIA }\end{array}$ & $\begin{array}{l}\text { - envolve a análise das expectativas e requisitos dos clientes e o } \\
\text { fornecimento documentado destas informações ao projeto e fabri- } \\
\text { cação. }\end{array}$ \\
\hline $\begin{array}{l}\text { 8. QUALIDADE EM } \\
\text { ESPECIFICAÇÃO E } \\
\text { PROJETO }\end{array}$ & $\begin{array}{l}\text { - envolve as atividades da especificação e do projeto do produto, com } \\
\text { definição dos métodos de ensaios, qualificação do projeto, análise } \\
\text { crítica do projeto ensaios piloto e liberação para produção. }\end{array}$ \\
\hline $\begin{array}{l}\text { 9. QUALIDADE NA } \\
\text { AQUISIÇÃO }\end{array}$ & $\begin{array}{l}\text { - envolve todas as fases de compra de matérias primas produtos e } \\
\text { serviços, com estreito relacionamento com os fornecedores, de forma } \\
\text { - rimplementar constantemente a qualidade: } \\
\text { - requisitos para especificação, plano de verificação; } \\
\text { - métodos de verifiçação e inspeção de recebimento; } \\
\text { - registros e certificação da qualidade. }\end{array}$ \\
\hline $\begin{array}{l}\text { 10. QUALIDADE NA } \\
\text { PRODUÇÃO }\end{array}$ & $\begin{array}{l}\text { - envolve todas as fases de planejamento, produção e controle de } \\
\text { fabricação; } \\
\text { - planejamento de controle da produção; } \\
\text { - capacidade de processo. }\end{array}$ \\
\hline $\begin{array}{l}\text { 11. CONTROLE DE } \\
\text { PRODUÇÃO }\end{array}$ & $\begin{array}{l}\text { - envolve o controle da rastreabilidade dos materiais, manutenção de } \\
\text { equipamentos, processos especiais, documentação, controle das } \\
\text { alterações de processos, o estado de inspeção e controle dos não } \\
\text { conformes. }\end{array}$ \\
\hline $\begin{array}{l}\text { 12. VERIFICAÇÃO DE } \\
\text { PRODUTO }\end{array}$ & $\begin{array}{l}\text { - envolve os ensaios e inspeções realizados, conforme o plano de } \\
\text { produção, durante o processo e no produto acabado. }\end{array}$ \\
\hline $\begin{array}{l}\text { 13. CONTROLE DE } \\
\text { EQUIPAMENTOS } \\
\text { DE MEDIÇÃO E } \\
\text { ENSAIO }\end{array}$ & $\begin{array}{l}\text { - envolve as ações de identificação dos equipamentos, sua aferição } \\
\text { contra os padrões nacionais, calibração e registros, tanto na empresa } \\
\text { como nos fornecedores. }\end{array}$ \\
\hline $\begin{array}{l}\text { 14. NÃO CONFORMI- } \\
\text { DADE }\end{array}$ & $\begin{array}{l}\text { - identificação de problemas, segregação dos produtos não conformes, } \\
\text { análise, disposição e documentação. }\end{array}$ \\
\hline 15. AÇÃO CORRETIVA & $\begin{array}{l}\text { - resolução de problemas por meio da ação imediata, análise e } \\
\text { bloqueio por meio de ação no processo e alterações permanentes, de } \\
\text { forma documentada. }\end{array}$ \\
\hline $\begin{array}{l}\text { 16. MANUSEIO E } \\
\text { FUNÇÕES PÓS } \\
\text { PRODUÇÃO }\end{array}$ & $\begin{array}{l}\text { - envolve as atividades de manuseio, identificação, armazenamento, } \\
\text { embalagem, expedição, serviços pós venda e retro-alimentação das } \\
\text { informações. }\end{array}$ \\
\hline $\begin{array}{l}\text { 17. DOCUMENTAÇÃO } \\
\text { E REGISTROS DA } \\
\text { QUALIDADE }\end{array}$ & $\begin{array}{l}\text { - prover documentação suficiente para acompanhar a obtenção da } \\
\text { qualidade no produto e a eficácia do sistema de gestão da qualidade, } \\
\text { fabricante, fornecedores e clientes. } \\
\text { - envolve desenhos, especificações, procedimentos, manuais, re-gistros } \\
\text { de inspeções/ensaios, relatórios de auditoria/aferição, etc. }\end{array}$ \\
\hline 18. PESSOAL & $\begin{array}{l}\text { - envolve as atividades de treinamento/educação, qualificação, } \\
\text { motivação para todos os funcionários da empresa e a medida do grau } \\
\text { de satisfação. }\end{array}$ \\
\hline $\begin{array}{l}\text { 19. SEGURANÇA E } \\
\text { RESPONSABILI- } \\
\text { DADE CIVIL DO } \\
\text { PRODUTO }\end{array}$ & $\begin{array}{l}\text { - envolve os aspectos de segurança da qualidade do produto ou } \\
\text { serviço: identificação das normas de segurança, testes de qualificação } \\
\text { do projeto, instruções e advertência aos usuários, meios de rastreabi- } \\
\text { lidade. }\end{array}$ \\
\hline
\end{tabular}




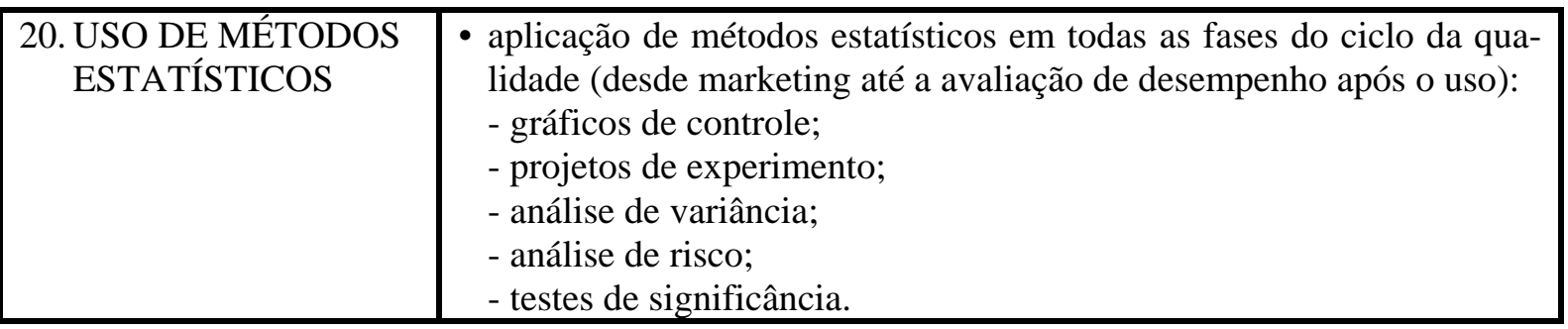

\title{
Quadro 3: Correspondência entre os Elementos da Qualidade
}

\author{
LEGENDA \\ * Requisito pleno + Menos rigoroso que na NB-9001 \\ $x$ Menos rigoroso que na NB-9002 - Elemento ausente
}

\begin{tabular}{|c|c|c|c|c|}
\hline \multirow{2}{*}{$\begin{array}{c}\text { ITEM } \\
\text { (Subitem) } \\
\text { NB-9004 }\end{array}$} & \multirow[t]{2}{*}{ TÍTULO } & \multicolumn{3}{|c|}{$\begin{array}{l}\text { Item correspondente (ou } \\
\text { subitem) números na }\end{array}$} \\
\hline & & NB-9001 & NB-9002 & NB-9003 \\
\hline 4 & - Responsabilidade da administração & $4.1 *$ & $4.1+$ & $4.1 \mathrm{x}$ \\
\hline 5 & - Princípios do sistema da qualidade & $4.2 *$ & $4.2 *$ & $4.2+$ \\
\hline 5.4 & - Auditoria do sistema da qualidade (interna) & $4.17 *$ & $4.16+$ & - \\
\hline 6 & $\begin{array}{l}\text { - Economia - considerações sobre custos } \\
\text { relacionados com a qualidade }\end{array}$ & - & - & - \\
\hline 7 & $\begin{array}{l}\text { - Qualidade em “MARKETING” (análise crítica } \\
\text { de contrato) }\end{array}$ & $4.3 *$ & $4.3 *$ & - \\
\hline 8 & $\begin{array}{l}\text { - Qualidade na especificação e projeto (controle } \\
\text { de projeto) }\end{array}$ & $4.4 *$ & - & - \\
\hline 9 & - Qualidade na aquisição (compras) & $4.6 *$ & $4.5 *$ & - \\
\hline 10 & - Qualidade na produção (controle de processo) & $4.9 *$ & $4.8 *$ & - \\
\hline 11 & - Controle de produção & $4.9 *$ & $4.8 *$ & - \\
\hline 11.2 & $\begin{array}{l}\text { - Controle e rastreabilidade de materiais } \\
\text { (identificação e rastreabilidade de produtos) }\end{array}$ & $4.8 *$ & $4.7 *$ & $4.4+$ \\
\hline 11.7 & $\begin{array}{l}\text { - Controle do estado de verificação (situação da } \\
\text { inspeção e ensaios) }\end{array}$ & $4.12 *$ & $4.11 *$ & $4.4+$ \\
\hline 12 & - Verificação de produtos (inspeção e ensaios) & $4.10 *$ & $4.9 *$ & $4.5+$ \\
\hline 13 & $\begin{array}{l}\text { - Controle de equipamentos de mediação e } \\
\text { ensaios (equipamentos de inspeção, mediação e } \\
\text { ensaios) }\end{array}$ & $4.11 *$ & $4.10 *$ & $4.6+$ \\
\hline 14 & $\begin{array}{l}\text { - Não conformidade (controle de produto não } \\
\text { conforme) }\end{array}$ & $4.13 *$ & $4.12 *$ & $4.8+$ \\
\hline 15 & - Ação corretiva & $4.14 *$ & $4.13 *$ & - \\
\hline 16 & $\begin{array}{l}\text { - Funções de manuseio e pós-produção, (manu- } \\
\text { seio, armazenamento, embalagem e expedição) }\end{array}$ & $4.15 *$ & $4.14 *$ & $4.9+$ \\
\hline 16.2 & - Serviços pós-venda & $4.19 *$ & - & - \\
\hline 17 & $\begin{array}{l}\text { - Documentação e registros da qualidade (con- } \\
\text { trole de documentos) }\end{array}$ & $4.5 *$ & $4.4 *$ & $4.3+$ \\
\hline 17.3 & - Registros da qualidade & $4.16 *$ & $4.15 *$ & $4.10+$ \\
\hline 18 & - Pessoal (treinamento) & $4.18 *$ & $4.17+$ & $4.11 \mathrm{x}$ \\
\hline 19 & $\begin{array}{l}\text { - Segurança e responsabilidade civil pelo fato do } \\
\text { produto }\end{array}$ & - & - & - \\
\hline 20 & - Uso de método estatístico (técnicas estatísticas) & $4.20 *$ & $4.18 *$ & $4.12+$ \\
\hline- & - Produtos fornecidos pelo comprador & $4.7 *$ & $4.6 *$ & - \\
\hline
\end{tabular}


$\mathrm{D}$ e acordo com as discussões preliminares do GNOP, sobre a proposta de pesquisa a ser encaminhada, ficou decidido que o parâmetro para uniformização da amostra seria a certificação da empresa pela ISO 9002. Assim, caber-nos-ia avaliar a implantação do Programa de Qualidade que habilitou a empresa à obtenção do certificado, ou, caso a empresa já tivesse um Programa de Qualidade, ou Sistema de Garantia da Qualidade, quais as modificações e/ou adaptações introduzidas para a ISO 9000.

Outro parâmetro importante, foi o de que não nos caberia avaliar o atendimento aos requisitos da ISO 9002, uma vez que partíamos de empresas que já haviam sido auditadas e certificadas. Deveríamos sim, nos ater a "estratégia" e resultados da implantação da ISO 9000. Para avaliar essa estratégia seria importante obter informações, em um primeiro momento, da pessoa ou grupo de pessoas diretamente ligado à coordenação das atividades de certificação e/ou controle de qualidade.

Feitas essas considerações, foi preparada uma proposta que, depois de discutida pelo GNOP, deu origem a um questionário que foi enviado às empresas. Rediscutido e ampliado, o questionário originou também o roteiro de visitas utilizado na segunda etapa da pesquisa.

Conforme relação publicada pela revista CQ - Controle da Qualidade (out. 1994), até outubro de 1993 havia 112 empresas certificadas pela ISO 9000 no Brasil. O questionário foi enviado a essas empresas e, desse total, recebemos resposta de 20 empresas (18,7\%). Em uma primeira avaliação 0 número foi considerado satisfatório, levando-se em conta que:

- não foi feito nenhum tipo de contato com as empresas, a não ser pela própria carta de encaminhamento do questionário;

- tratava-se de uma pesquisa acadêmica, sem a intermediação de entidades de classe como por exemplo as Federações de Indústrias;

- o questionário era aberto, necessitando um comprometimento razoável de tempo, por parte do responsável, para sua resposta;

- o questionário foi enviado em um período difícil para a maioria das empresas (pouco antes das festas de final de ano e do período de férias), o que certamente dificultou a liberação de pessoas para o seu preenchimento;

- o período de recebimento do questionário coincidiu com as vésperas das festas de final de ano, em que há um grande acúmulo de correspondência nos correios, provocando aumento da probabilidade de extravio da correspondência.

De qualquer forma, sem levar em conta o número de questionários devolvidos, este primeiro questionário apresentou, em alguns itens, um alto grau de dispersão nas respostas apresentadas. Por meio da experiência de alguns integrantes do GNOP com Programas de Qualidade e com a questão da certificação, além de idéias coletadas diretamente junto às empresas já visitadas, foi possível agrupar conjuntos dessas respostas e tirar algumas conclusões interessantes.

Ainda assim, chegou-se à conclusão de que seria conveniente enviar um segundo questionário, desta vez fechado, para tirar dúvidas e confirmar as hipóteses levantadas. O novo questionário manteve os mesmos temas abordados anteriormente, de uma forma mais direta e sintética, e foi enviado às mesmas 112 empresas. Desta vez o número de questionários respondidos chegou a 54 (48,5\%), uma amostra bastante expressiva da população estudada.

Finalmente, com base nas informações coletadas por meio dos questionários, a pesquisa foi completada e suas conclusões reforçadas a partir das visitas (às empresas) realizadas pelos grupos integrantes do GNOP. Nesta etapa, cada grupo (GPI-RJ, TTO-SP, DEP-MG, PPGEP-RS) ficou 
responsável pela visita a três empresas na sua região de atuação.

\section{Principais Informações e Resultados}

\section{a) Primeiro questionário:}

$\mathrm{O}$ primeiro item abordado no questionário tratava da visão das empresas acerca da ISO 9000. Neste item, apenas $14 \%$ das respostas apontaram a ISO 9000 como um instrumento para a melhoria da qualidade. A grande maioria das respostas (81\%) indicou a ISO 9000 como um instrumento para o estabelecimento de dire-trizes para a padronização (registro) de ativi-dades, ou como um conjunto de normas para atendimento de requisitos de certificação.

Em outro item relacionado à visão das empresas à respeito da ISO 9000, o referente aos fatores que levaram as empresas à sua implantação, a questão da certificação aparece novamente, com $12 \%$ das respostas apontando para exigências contratuais e $14 \%$ como base ou fator estratégico para a qualidade total. As outras respostas se concentraram basicamente em: competir no mercado interno (20\%) e competir no mercado externo (25\%). Neste caso, principalmente no que diz respeito ao mercado externo, o competir está intimamente relacionado à certificação internacional, conforme informações prestadas no item anterior.

Sobre o diagnóstico da situação vigente e na definição da estratégia de implantação, observou-se uma grande predominância de desenvolvimento interno das empresas, seja por meio da estrutura já existente para a qualidade (30\%), seja por meio da criação de grupos de estudos multidisciplinares (33\%). Apenas 20\% das respostas apontaram para diagnósticos feitos por empresas de consultoria especializadas.

Este posicionamento é confirmado pela resposta a itens subseqüentes, que, no caso da questão 4 do questionário, indica que em $41 \%$ das empresas já havia, à época da implantação da ISO 9000, algum sistema de garantia da qualidade. Além disso, 49\% das respostas à questão 5 indicam que a principal orientação estratégica do programa foi o desenvolvimento interno. Finalmente, $16 \%$ das respostas falam também em visitas a empresas certificadas, e outros $16 \%$ em treinamento externo.

Com base nessas estratégias, nas respostas apresentadas à sexta questão, ficou caracterizada a centralização do programa de implantação da ISO 9000 na figura do gerente de controle e/ou gerente de garantia da qualidade. Em cerca de $20 \%$ das respostas apontou-se para a criação dessa função, anteriormente inexistente. Em 18\% das respostas o programa foi conduzido pela própria equipe de controle de qualidade. Por outro lado, 30\% das respostas mencionam o trabalho de equipes multidisciplinares, criadas para a condução do programa. Um dado importante são as respostas (10\%) que apontam para a criação de um comitê da qualidade, formado pela alta administração

No item referente às principais etapas do programa a dispersão foi muito grande, não permitindo estabelecer-se uma estatística das respostas apresentadas. De qualquer forma, algumas etapas como: treinamento, avaliação, elaboração dos manuais, auditoria interna e certificação são constantemente assinaladas.

Um grande elemento facilitador apontado (32\%) foi o comprometimento da alta administração. Outros elementos importantes foram: a existência de um sistema formalizado de garantia da qualidade (11\%), a experiência em outros processos de certificação (11\%) e a participação do pessoal das áreas (22\%).

Como elementos dificultadores vale a pena ressaltar: envolvimento parcial dos funcionários(15\%), resistência à documentação (11\%), resistência à mudança (11\%), falta de conhecimento em relação à norma 
(15\%) e pouca participação das áreas comercial e administrativa.

Os organismos certificadores mais procurados são o INMETRO (36\%) e o BVQI (36\%). Completam a lista a ABS (20\%) e o Lloyd's (8\%). As justificativas da escolha do INMETRO incluem: a esperança de reconhecimento pela Comunidade Européia como agente certificador (22\%), abrangendo aí o aspecto menor custo; a visão que o organismo tem dos problemas nacionais (22\%) e o reconhecimento do organismo no âmbito nacional e do MERCOSUL (56\%).
Finalmente, como principais resultados positivos advindos da implantação da ISO 9000, as respostas apontam, dentre outros: a melhoria da imagem da empresa (28\%), a conscientização para a questão da qualidade (28\%), a melhoria na qualidade do produto (17\%), a redução dos custos da má qualidade (16\%) e o aumento das exportações (5\%). Por outro lado, $12 \%$ de todas as respostas deixam claro que a implantação da ISO 9000 não teve nenhum reflexo no resultado de vendas.

\section{b) Segundo questionário:}

De um modo geral, o segundo questionário confirmou as informações obtidas com o primeiro, com respostas mais claras e diretas. Em primeiro lugar confirmou a informação de que apenas um número muito pequeno de empresas certificadas ( $9 \%$ ) não haviam tomado nenhuma iniciativa voltada para a melhoria da qualidade, a não ser processos simples de inspeção de qualidade no produto final. Dentre aquelas empresas que já apresentavam inciativas mais abrangentes voltadas para a melhoria da qualidade, $17 \%$ mantinham sistemas de qualidade para atender exigências contratuais, $27 \%$ tinham sistemas de controle de processo, 52\% tinham atividades documentadas e padronizadas.

Sobre o interesse específico pela ISO 9000 , os fatores mais importantes, apontados pelas empresas, foram: obtenção de certificado de qualidade com reconhecimento internacional (57\%), atualização do sistema de qualidade já existente (27\%), decisão de cúpula no âmbito da corporação (26\%), exigências contratuais (17\%).

Estes números parecem indicar, ao contrário dos do questionário anterior, um direcionamento maior da certificação ISO 9000 para o mercado internacional. Por outro lado, na hora de investir na implantação da ISO 9000, apenas 9\% das empresas se orientaram primordialmente para o mercado externo, $13 \%$ achavam o mercado interno mais importante e $67 \%$ atribuíam a mesma importância aos mercados interno e externo. Além disso $11 \%$ das empresas não visavam ganhos imediatos em competitividade.

No primeiro questionário, um dado surpreendente foi a baixa expectativa das empresas quanto à redução de custos como um dos fatores importantes na implantação de um Programa de Qualidade, baseado na ISO 9000. Para nos certificarmos no tocante a esta observação foi feita uma pergunta para averiguar até que ponto a possibilidade de redução de custos teria influenciado a decisão de implantar a ISO 9000. As respostas revelaram pouca influência (56,6\%), muita influência (28,3\%) e nenhuma influência $(15,1 \%)$.

Quanto à ocorrência de investimentos em tecnologia durante a implantação da norma, $44,4 \%$ das empresas responderam não ter havido necessidade de investimentos significativos. Dentre aquelas que realizaram investimentos, chegou-se ao seguinte perfil: integração informatizada da produção (35\%), MRP ou Kanban (13\%), máquinas e/ou equipamentos de processo (44\%), CAD (17\%), equipamentos para metrologia (5\%). De todos estes investimentos, 53\% estavam associados à implantação da ISO 9000. 


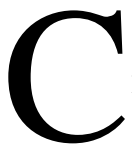

om base nos resultados apurados e nas visitas realizadas, podemos tirar algumas conclusões importantes acerca do processo de implantação da ISO 9000. Uma das mais importantes, é que a série ISO 9000, pensada como um instrumento para difundir o conceito de Qualidade entre as empresas, não tem sido vista dessa forma por grande parte das empresas brasileiras. Assim é que a maioria das respostas aponta para a ISO como uma simples questão de padronização e registro de processos para garantir uma certificação.

Essa visão reflete, inclusive, algums pontos de vista teóricos, que são abordados na discussão sobre a sua implantação, como por exemplo o de que a ISO 9000 seria na verdade uma barreira técnica erguida pelo Mercado Comum Europeu. Em outras palavras, os países da Comunidade Européia, ao se unirem em bloco e abolir barreiras comerciais, se preocuparam em deixar mecanismos de controle à entrada de produtos estrangeiros.

Durante muito tempo, os defensores desta idéia reforçaram seu ponto de vista apontando para a dificuldade que organismos de certificação fora da Europa (Japão, EUA, Brasil, etc), ainda que com grande credibilidade nacional e internacional, tinham para serem reconhecidos pelo bloco europeu como agentes certificadores da ISO 9000 para a Europa.

Sem querer entrar nessa discussão, é importante observar que ainda que não fosse esse o interesse do bloco europeu, na prática, a exigência de certificação para permanecer em mercado tão promissor, levou grande parte das empresas a uma visão distorcida da ISO 9000. Na prática, em alguns casos observados por meio das visi-tas realizadas na segunda etapa da pesquisa, a exigência contratual do Mercado Comum Europeu, trouxe um certo "temor" às empre-sas. Como apontam VALLE \& PEIXOTO (1994), em um primeiro momento "houve uma espécie de pânico generalizado, temendo-se que esta exigência tornasse difícil de ser atendida. Pensava-se que o processo de certificação envolveria avaliações rigorosas dos produtos, o que na verdade não faz parte do escopo das normas". Ainda de acordo com os autores, a partir dos primeiros processos de certificação este temor desapareceu e o país está próximo de atingir o número de 500 empresas certificadas.

Um outro aspecto interessante da pesquisa é revelar que, no caso brasileiro, o interesse pela ISO 9000 não se verifica apenas naquelas empresas preocupadas com o mercado externo. De fato, a preocupação pela ISO 9000 se dividiu em partes iguais entre empresas preocupadas com o mercado externo e interno. De qualquer forma, como visto no item anterior, a razão para tal preocupação não parece estar fundamentada em uma maior preocupação com a qualidade.

Talvez a melhor explicação para a preocupação execessiva com a certificação, seja encontrada em algumas empresas, principalmente estatais, que com seu enorme poder de pressão, junto a um grande número de fornecedores (PETROBRÁS, CVRD, Sistema Eletrobrás, etc), tem colocado a ISO 9000 como uma tendência do mercado interno brasileiro. Essa tendência foi confirmada pelo governo brasileiro, quando do lançamento do Programa Brasileiro de Qualidade e Produtividade - PBQP, no qual a ISO 9000 (NB 9000) é colocada claramente como uma futura exigência contratual de todo o sistema fornecedor para empresas estatais. Algumas empresas visitadas na segunda etapa da pesquisa confirmaram essa idéia.

A pesquisa mostrou também um certo conflito, entre as respostas apresentadas, no que diz respeito ao papel e ao envolvimento da alta administração das empresas. De fato, apesar dessa participação ter sido apontada como agente facilitador por $32 \%$ das empresas, apenas $10 \%$ das respostas mencionam a criação de comitês da alta administração. Assim, reforçando um pouco mais a questão sobre a visão de curto prazo (exigência contratual) acerca do processo de 
implantação da ISO 9000 nas empresas, parece que a alta administração está ciente da necessidade dela como elemento de sobrevivência. Porém, essa mesma alta administração ainda não encontrou seu papel em um processo de longo prazo, qual seja o da implantação de um Programa de Gestão da Qualidade em um nível estratégico, voltado para a melhoria efetiva dos produtos e processos.

Outro dado interessante a observar, é que os elementos dificultadores apresentam uma dispersão entre as empresas, muito maior do que os facilitadores. Talvez esse seja um ponto favorável à implantação da ISO 9000 e ajude a entender o sucesso que várias empresas estão tendo na obtenção da certificação. Ou seja, apesar de haver vários aspectos dificultadores, as empresas têm conseguido aglutinar mais facilmente aqueles aspectos favoráveis.

Com certeza, outro ponto favorável na obtenção da certificação por parte de empresas brasileiras, foi o trabalho de várias destas empresas, de já terem iniciado programas de qualidade, em um momento muito anterior ao atual, e de terem participado de processos de certificação, notadamente entre os fornecedores da PETROBRÁs. De fato, como a pesquisa revela (VALLE \& PEIXOTO, 1994) a adoção da ISO 9000 foi precedida em muitos casos, por métodos organizacionais e padrões de sistemas de qualidade. Por outro lado, estas atividades se encontravam muitas vezes desarticuladas e a implantação da norma veio justamente promover sua integração.

Como elemento dificultador algumas empresas apontaram a pouca participação das áreas comercial e administrativa. Esta é uma característica importante e que precisa ser levada em consideração por aquelas em processo de certificação. De fato, a ISO 9000, apesar de ter sido pensada como uma referência geral (indústria e serviço), acabou tornando-se uma referência para chão-defábrica. Para contornar essa distorção, o comitê ISO preparou a ISO 9004 parte II, que apresenta uma fonte de referência voltada para processos de prestação de serviços.

Finalmente, como conclusão importante, pode-se observar que os maiores resultados da implantação da ISO se verificam no tocante à melhoria da imagem da empresa. $\mathrm{Na}$ prática, além da garantia de acesso a mercados, a ISO 9000 tem-se caracterizado como um elemento mercadológico, ainda que várias respostas indiquem que não houve aumento nas vendas após a implantação.

\section{Referências Bibliográficas:}

GNOP: Informativo do Grupo Nacional de Organização da Produção - GNOP - Número 1, Belo Horizonte, maio 1994.

GNOP: Informativo do Grupo Nacional de Organização da Produção - GNOP - Número 2, Belo Horizonte, agosto 1994.

GNOP: Informativo do Grupo Nacional de Organização da Produção - GNOP - Número 3, Belo Horizonte, novembro 1994.

ABNT: NB 9000/ISO 9000, Normas de Gestão da Qualidade e Garantia da Qualidade. ABNT, Junho 1990.
CONTROLE DA QUALIDADE: "Ensaio, Instrumentação, Medição e Controle de Processos”. Controle da Qualidade. Editora Barra Ltda, no 17, p. 4271, outubro 1993.

VALLE, R. \& PEIXOTO, J.A.: "Certificação da Qualidade e Opções Organizacionais: Histórico e estudos de caso no Brasil”. XVIII Encontro Anual da ANPOCS, Caxambu, novembro 1994.

\section{ASSESSMENT OF QUALITY PROGRAMNS BY THE IMPLANTATION OF ISO 9000}


The Grupo Nacional de Organização da Produção - GNOP - has completed research concerning the implementation of Quality Programs in Brazilian enterprizes, based on the ISO 9000 certification process. As a first step, questionnaires were sent to those companies already certified by the ISO 9000. Based on the first results, a second questionnaire was prepared and sent out again to those companies. Finally, the information gathered was evaluated and analysed by means of technical visits to twelve companies, regionally distributed among the groups that take part in the GNOP. This paper presents the main results.

Key-words: ISO 9000, Quality Assurance. 